\title{
Assessment of a new transtelephonic portable spirometer
}

Shimon Abboud, Israel Bruderman

\begin{abstract}
Background - A new portable spirometer, the Spirophone, has been developed that records a subject's blow and can then transmit all the data by telephone to a receiving centre for analysis and comment. Tests of this device were undertaken to determine its accuracy and reliability. Methods - The performance of the Spirophone was tested using computer generated wave forms, by delivering blows from calibrated syringes at different flows, and by comparing subjects' blows with those recorded with a commercial spirometer.
\end{abstract}

Results - Using computer generated wave forms all lung function indices were accurate to within $1 \%$ and blows delivered from calibrating syringes were accurate to within $5 \%$. When subjects performed repeated forced vital capacity (FVC) manoeuvres there were no significant differences between lung function indices recorded with the Spirophone and with a commercial spirometer. With the Spirophone and commercial spirometer in series the FVC and forced expiratory volume in one second $\left(F E V_{1}\right)$ were within $5 \%$ of each other in nine out of 10 healthy subjects.

Conclusion - The Spirophone recorded maximal forced expiratory manoeuvres with acceptable accuracy, reliability, and reproducibility, and this system offers the ability to monitor a patient's lung function at a centre remote from the patient.

(Thorax 1996;51:407-410)

Keywords: spirometry, FVC test, lung function parameters.

Home monitoring of lung function is becoming increasingly important in the management of asthma, chronic obstructive lung disease,${ }^{1-3}$ and after lung transplantation. The most widely used devices in patient self-monitoring of daily medication and in clinical drug efficacy studies have been peak flow meters, and portable spirometers have also been used to measure forced vital capacity (FVC), forced expiratory volume in one second $\left(\mathrm{FEV}_{1}\right)$, and peak expiratory flow (PEF). A transtelephonic portable personal spirometer (Spirophone AG-SP) with a remote receiving centre (CG-8010) has been developed (Card Guard, Rishon Le Zion, Israel) which can measure lung function indices at a patient's home and transmit the data to a remote receiving centre for analysis of both spirograms and flow-volume curves. We have evaluated the accuracy, reliability, and reproducibility of this system in the laboratory and in an operational setting.

\section{Methods}

The Spirophone comprises an unheated Fleisch pneumotachograph with differential pressure transducer, microprocessor, memory, and speaker which operates with a 9 volt battery and samples the flow signal at $400 \mathrm{~Hz}$ using a 12 bit A/D converter. The flow meter is $150 \mathrm{~mm}$ long and accepts standard $28 \mathrm{~mm}$ internal diameter mouthpieces. Ambient temperature is recorded to within $1{ }^{\circ} \mathrm{C}$ during the blow as recommended by the American Thoracic Society, ${ }^{4}$ and its operational range is up to eight litres in volume, $14 \mathrm{l} / \mathrm{s}$ flow, and 30 second duration for recording vital capacity (VC) and up to 25 seconds for FVC. The following spirometric indices are calculated by the microprocessor of the Spirophone: VC, FVC, FEV and $\mathrm{FEV}_{3}, \mathrm{PEF}$, and the maximal expiratory flow when $75 \%, 50 \%$ and $25 \%$ of FVC remain to be expired $\left(\mathrm{MEF}_{75}, \mathrm{MEF}_{50}\right.$, and $\left.\mathrm{MEF}_{25}\right)$. The $\mathrm{FEV}_{1}$ and $\mathrm{FEV}_{3}$ are calculated using back extrapolation ${ }^{4}$ and are also expressed as a percentage of VC and FVC $\left(\mathrm{FEV}_{1} / \mathrm{VC}, \mathrm{FEV}_{1} /\right.$ FVC, etc). The Spirophone records one blow at a time and then modulates the data into tones for transmission by telephone to a receiving centre using acoustic coupling. The transmission of data takes 30 seconds which includes the application of a data verification algorithm.

The receiving centre requires a 486 personal computer with $4 \mathrm{Mb}$ RAM, a receiving demodulator unit, and a printer. On receiving a call from a patient, an operator at the receiving centre instructs the patient to transmit the data by placing the phone handset on to the Spirophone's speaker. The receiving unit demodulates the data, performs a BTPS correction (see Appendix), and presents it on screen with the spirogram and flow-volume curve. If the blow is deemed acceptable according to ATS recommendations ${ }^{4}$ it is then stored in a database and the patient can then be instructed with respect to further blows or their clinical management. The system is only suitable for patients who have been assessed as able to perform the expiratory manoeuvres satisfactorily when unsupervised.

The Spirophone was compared with a commercial Fleisch pneumotachograph electronic spirometer (Fukuda Spiroanalyzer Model ST250) with an identical operational range but whose heating element we disconnected during measurements with calibrated syringes. 
Table 1 Results from testing with analogue signals simulating forced vital capacity manoeuvres

\begin{tabular}{|c|c|c|c|c|c|c|c|}
\hline & $\begin{array}{l}F V C \\
\text { (l) }\end{array}$ & $\begin{array}{l}F E V_{1} \\
\text { (l) }\end{array}$ & $\begin{array}{l}F E V_{3} \\
\text { (l) }\end{array}$ & $\begin{array}{l}P E F \\
(l / s)\end{array}$ & $\begin{array}{l}M E F_{75} \\
(I / s)\end{array}$ & $\underset{(l / s)}{M E F_{50}}$ & $\begin{array}{l}M E F_{25} \\
(l / s)\end{array}$ \\
\hline \multicolumn{8}{|l|}{ Test 1} \\
\hline Actual & 1.00 & 0.89 & 1.00 & 3.00 & $2 \cdot 39$ & 3.00 & $2 \cdot 39$ \\
\hline Error & 0.00 & 0.00 & 0.00 & 0.01 & 0.00 & 0.00 & 0.00 \\
\hline \multicolumn{8}{|l|}{ Test 2} \\
\hline Actual & 3.00 & $2 \cdot 68$ & 3.00 & $7 \cdot 00$ & $5 \cdot 57$ & $7 \cdot 00$ & $5 \cdot 57$ \\
\hline Error & 0.00 & 0.00 & 0.00 & 0.01 & 0.01 & 0.01 & 0.03 \\
\hline \multicolumn{8}{|l|}{ Test 3} \\
\hline Actual & $6 \cdot 00$ & $5 \cdot 37$ & $6 \cdot 00$ & $12 \cdot 00$ & $9 \cdot 55$ & $12 \cdot 00$ & $9 \cdot 55$ \\
\hline Error & -0.01 & 0.00 & -0.01 & -0.04 & 0.01 & -0.05 & 0.00 \\
\hline \multicolumn{8}{|l|}{ Test 4} \\
\hline Actual & 6.00 & $2 \cdot 37$ & $5 \cdot 33$ & 3.00 & $2 \cdot 39$ & 3.00 & $2 \cdot 39$ \\
\hline Error & -0.01 & 0.02 & 0.00 & 0.02 & 0.00 & -0.01 & 0.01 \\
\hline
\end{tabular}

$\mathrm{FVC}=$ forced vital capacity; $\mathrm{FEV}_{1}, \mathrm{FEV}_{3}=$ forced expiratory volume in one and three seconds; $\mathrm{PEF}=$ peak expiratory flow; $\mathrm{MEF}_{75}, \mathrm{MEF}_{50}$ and $\mathrm{MEF}_{25}=$ normal expiratory flow when $75 \%$, $50 \%$ and $25 \%$ of FVC remain to be expired.

The electronic circuitry and microprocessor software of the Spirophone were tested with computer simulated "Gaussian" flow-time signals (symmetric signal around the mean) applied directly to the A/D converter. ${ }^{5}$ The linearity of the Spirophone was tested by discharging through the Spirophone a computer driven volume-time ramp profile - that is, constant flow - at different flows using a three litre servocontrolled piston pump. ${ }^{6}$ One litre and three litre syringes were then discharged through the Spirophone and the commercial spirometer after each was calibrated for ambient temperature with no BTPS correction being applied. The syringes were fitted directly to the spirometers to minimise turbulence and resonance. ${ }^{7}$

Tests with human subjects were conducted with the ambient temperature between $21^{\circ} \mathrm{C}$ and $23^{\circ} \mathrm{C}$ and barometric pressure at $750-755 \mathrm{~mm} \mathrm{Hg}$. One normal subject and two patients performed 10 repeated FVC manoeuvres separately through each spirometer. The Spirophone and commercial spirometer were then connected in series and 10 normal subjects performed FVC manoeuvres. ${ }^{589}$ Fifteen patients (nine women) aged 13-64 years with evidence of airflow limitation performed relaxed and forced VC manoeuvres separately with the Spirophone and commercial spirometer. $^{9-12}$ Three acceptable blows were recorded and the best results were used for analysis. The Spirophone data were transmitted via a telephone in the same room.

Reliability and drift in calibration under typical home use were tested in nine Spirophones each calibrated with a one litre syringe and supplied with a new battery. Five patients each transmitted FVC tests daily from home for three months with the Spirophones being returned to the laboratory once a month for check
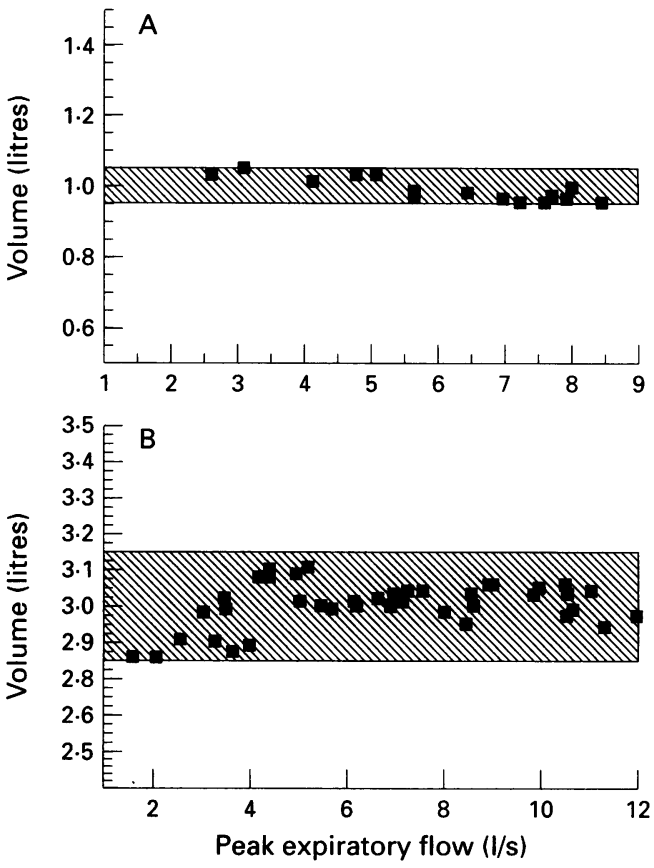

Figure 1 Recorded volumes of the Spirophone using forced vital capacity manoeuvres simulated by $(A)$ one litre and $(B)$ three litre calibrated syringe with variable emptying rates of air. The recorded volumes are presented as a function of the peak expiratory flows.

testing. Four other Spirophones were used to transmit FVC manoeuvres by telephone from the laboratory and were check tested on alternate days for 30 days. The check testing in each case consisted of inspection for damage, correct operation, battery status, and assessment of calibration.

Statistical analysis was by the paired Student's $t$ test with a probability of $5 \%$ being taken as significant.

\section{Results}

When tested with constant flows up to $14 \mathrm{l} / \mathrm{s}$ from a computer driven syringe the linearity of the Spirophone was found to meet the ATS recommendation ${ }^{4}$ of $\pm 0.2 \mathrm{l} / \mathrm{s}$ or $\pm 5 \%$ of the reading, whichever is the greater, with the maximum absolute and percentage error being $-0.098 \mathrm{l} / \mathrm{s}$ or $8 \cdot 2 \%$ ) at a flow of $1.21 / \mathrm{s}$. Table 1 shows the results when the circuitry of the Spirophone was tested with simulated signals and the greatest error was less than $1 \%$. Figure 1 shows the volumes recorded with the Spirophone when tested with calibrating syringes discharged with varying flows. The maximum error was within $\pm 5 \%$ of the true volume.

Table 2 Mean (SD) comparison of results of lung function tests obtained with repeated FVC tests

\begin{tabular}{|c|c|c|c|c|c|c|}
\hline \multirow[t]{2}{*}{ Parameter } & \multicolumn{2}{|l|}{ Control } & \multicolumn{2}{|l|}{ Patient 1} & \multicolumn{2}{|l|}{ Patient 2} \\
\hline & Spirophone & Spirometer* & Spirophone & Spirometer* & Spirophone & Spirometer* \\
\hline FVC (1) & $5.33(0.09)$ & $5 \cdot 13(0 \cdot 13)$ & $5.53(0.26)$ & $5.29(0 \cdot 10)$ & $2.95(0.21)$ & $3.04(0.09)$ \\
\hline $\mathrm{FEV}_{1}(\mathrm{l})$ & $4.29(0.13)$ & $4.37(0.06)$ & $3 \cdot 72(0 \cdot 11)$ & $3.79(0.08)$ & $2.47(0.15)$ & $2.59(0.05)$ \\
\hline $\mathrm{FEV}_{3}$ (l) & $5.28(0.16)$ & $5.02(0.22)$ & $4.94(0.09)$ & $5.03(0.07)$ & - & - \\
\hline PEF (1/s) & $10.02(0.63)$ & $9.65(0.34)$ & $8.95(0.68)$ & $9.20(0.39)$ & $5 \cdot 30(0 \cdot 29)$ & $5.23(0.24)$ \\
\hline $\mathrm{FEF}_{25}(\mathrm{l} / \mathrm{s})$ & $8.98(0.31)$ & $9 \cdot 18(0 \cdot 07)$ & $5 \cdot 76(0 \cdot 77)$ & $6.03(0.63)$ & $4.72(0.60)$ & $4 \cdot 82(0.13)$ \\
\hline $\mathrm{FEF}_{50}(\mathrm{l} / \mathrm{s})$ & $4.68(0.24)$ & $4.83(0 \cdot 28)$ & $3.44(0.23)$ & $3.25(0.09)$ & $2.87(0.33)$ & $2.84(0.09)$ \\
\hline $\mathrm{FEF}_{75}(1 / \mathrm{s})$ & $2 \cdot 10(0.20)$ & $2.38(0.11)$ & $1.23(0.10)$ & $1.23(0.01)$ & $1.33(0.17)$ & $1.43(0.06)$ \\
\hline
\end{tabular}

* Office spirometer.

For definition of terms see footnote to table 1 . 


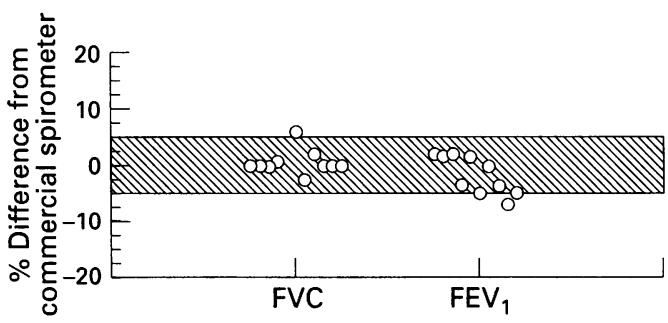

Figure 2 Differences for forced vital capacity (FVC) and forced expiratory volume in one second $(F E V)$ between the Spirophone and the commercial spirometer connected in series in 10 healthy volunteers.

Table 2 shows the results for 10 repeated FVC manoeuvres for a healthy subject and two patients with different spirometric abnormalities. The reproducibility of the Spirophone was comparable with that for the commercial spirometer and there were no significant differences between the spirometers for any of the lung function indices in any subject.

Figure 2 shows the comparison between the results from 10 subjects recorded with the Spirophone and commercial spirometer connected in series. The FVC and $\mathrm{FEV}_{1}$ were within $\pm 5 \%$ in nine of the 10 subjects, with all the results being within $\pm 7 \%$.

The results for the 15 patients with the Spirophone and the commercial spirometer were analysed according to the method of Altman
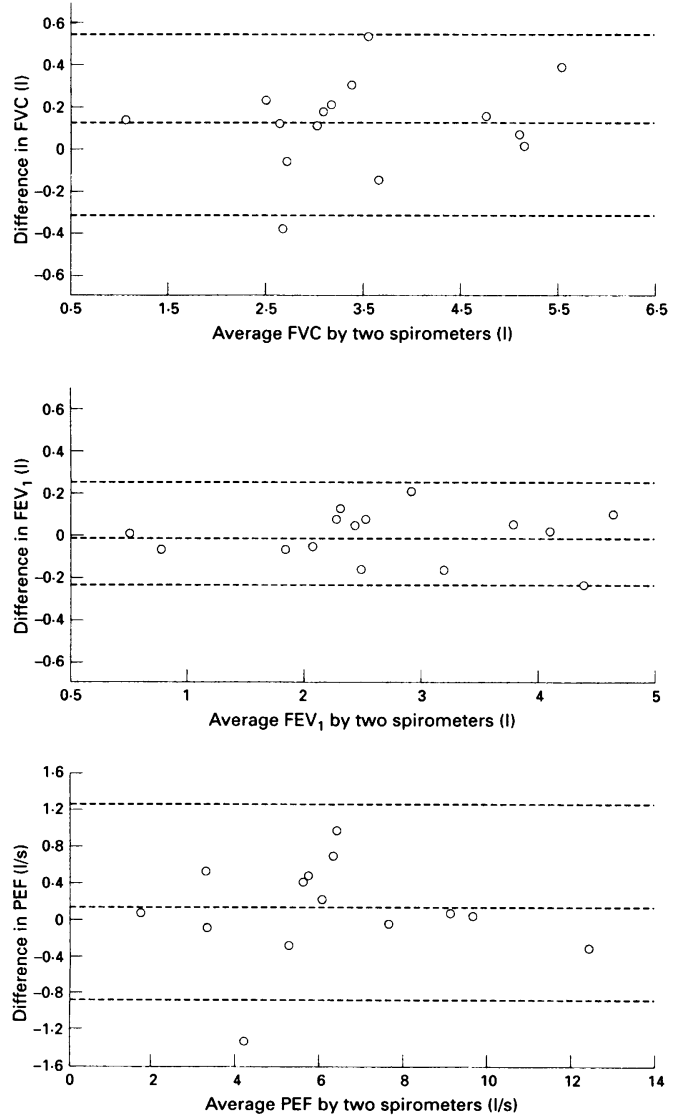

Figure 3 Comparison of forced vital capacity (FVC), forced expiratory volume in one second (FEV), and peak expiratory flow (PEF) in 15 patients obtained by the Spirophone and the commercial spirometer. The difference between the spirometers is plotted against the average. Mean and limits of agreement are presented. and Bland ${ }^{13}$ and fig 3 shows the plots for FVC, $\mathrm{FEV}_{1}$, and PEF. The results for all indices are presented in table 3 and show significantly lower readings with the Spirophone for relaxed $\mathrm{VC}$ and $\mathrm{MEF}_{25}$, with the differences not being related to the magnitude of the mean for the two spirometers. For all the other indices there was no significant difference and no trend in relation to mean value.

When the Spirophones were tested for three months at home and in the 30 day laboratory based study all performed reliably without recording or transmission failure. A battery change was needed after $90-100$ operations. The one litre volume calibrations were all accurate to within $5 \%$ throughout.

\section{Discussion}

The Spirophone system was reliable and accurate in both the recording and transmission of forced expiratory manoeuvres from a patient's home to a remote centre for analysis and comment. Such a system may have considerable merit in the management of certain patients. In the last 10-15 years asthma prevalence and mortality has been increasing in the USA ${ }^{1415}$ and other countries. Many asthmatic subjects perform home monitoring of PEF using simple hand held meters, and this may lead to improved management of their asthma. ${ }^{1617}$ However, in fatal asthma there is often pathological evidence of severe effects in small airways. ${ }^{18-20}$ Thus a portable spirometer such as the Spirophone, that is capable of monitoring both large and small airway function and can also verify patient compliance, may be advantageous. This would be especially true for patients living in remote areas or for those who have difficulty in reaching medical help due to disability or other circumstances. The cost of the Spirophone is about $£ 700$, the receiving unit is about $£ 4750$, and there is the additional cost of the computer at the receiving centre and the operator's time. However, it is possible that this transtelephonic system of patient administered spirometry may increase the cost effectiveness of patient management by timely intervention with changes in therapy and consequent avoidance of hospital admission. ${ }^{21}$

Our results in the 15 subjects with airways limitation showed less good agreement for indices with a greater reliance on patient effort such as FVC, PEF, and $\mathrm{MEF}_{75}$, with better agreement for $\mathrm{FEV}_{1}, \mathrm{FEV}_{3}, \mathrm{MEF}_{50}$, and $\mathrm{MEF}_{25}$ which are less effort dependent. Similar agreement was found for FVC and $\mathrm{FEV}_{1}$ by Gunawardena $e t a l^{9}$ in a study in humans. Because humans have their own inherent variability with repeated blows, ${ }^{22}$ the wider levels of agreement observed with certain indices may be expected. Our tests with the two spirometers in series may have influenced the readings as a result of cooling and effects on upstream geometry, ${ }^{23}$ but it seems unlikely that this could fortuitously lead to such good agreement between the spirometers.

It has previously been shown ${ }^{24}$ that accuracy validation of a spirometer with a calibrated syringe alone is not sufficient to demonstrate 
Table 3 Mean (SD) results for 15 subjects with airways limitation recorded with the Spirophone and commercial spirometers

\begin{tabular}{llllll}
\hline & Spirophone & Commercial & $p$ value & $\begin{array}{l}\text { Mean }(S D) \\
\text { differences }\end{array}$ & Limits of agreements \\
\hline VC & $3.21(1.21)$ & $3.44(1.23)$ & $<0.0005$ & $0.23(0.16)$ & +0.55 to -0.09 \\
FVC & $3.43(1.20)$ & $3.54(1.23)$ & NS & $-0.11(0.22)$ & +0.55 to -0.32 \\
FEV $_{1}$ & $2.68(1.20)$ & $2.68(1.20)$ & NS & $-0.001(0.12)$ & +0.25 to -0.24 \\
FEV $_{3}$ & $3.14(1.25)$ & $3.19(1.28)$ & NS & $0.04(0.12)$ & +0.28 to -0.19 \\
PEF $_{\text {MEF }}$ & $6.10(2.83)$ & $6.22(2.83)$ & NS & $0.12(0.56)$ & +1.23 to -0.99 \\
MEF $_{50}$ & $5.16(2.67)$ & $5.22(2.64)$ & NS & $0.06(0.51)$ & +1.08 to -0.96 \\
$\mathrm{MEF}_{25}$ & $1.35(0.89)$ & $3.00(1.71)$ & NS & $-0.02(0.33)$ & +0.64 to -0.69 \\
\hline
\end{tabular}

Mean difference $=$ mean of the commercial spirometer reading minus that from the Spirophon together with the limits of agreements for the differences; VC = vital capacity; $\mathrm{NS}=$ not significant. For definition of other terms see footnote to table 1.

how well a spirometer would perform with dynamic patient wave forms, and a sophisticated test using a computer-controlled mechanical pump with the 24 wave forms recommended by the $\mathrm{ATS}^{4}$ is necessary. ${ }^{624}$ In the present study a sophisticated computercontrolled mechanical pump was not available, and since dynamic wave form testing is essential, human data in a variety of test procedures were used.

The Spirophone uses an unheated pneumotachograph which may lead to thermal and condensation errors. ${ }^{25}$ These effects can be minimised, however, by placing the pneumotachograph on a fan blowing ambient air $^{26}$ between blows, and any such error would have affected both the spirometers used in our study and so could not have introduced a bias.

The Spirophone system has been shown to be reliable and accurate for forced expiratory manoeuvres and can be used as a diagnostic tool in clinical practice, in epidemiological studies, and in clinical drug efficacy studies. It may also overcome some of the limitations of the present home monitoring devices by providing important additional indices from the forced expiratory manoeuvre, by displaying spirograms and flow-volume curves to a technician or physician for analysis, and by allowing quality control over the blows recorded. However, since the blows are performed without visual supervision, the system is suitable only for patients who are able to perform the forced expiratory manoeuvre by themselves and can respond to advice given over the telephone.

\section{Appendix}

The BTPS correction was carried out using the formula below which is sufficiently accurate for clinical application ${ }^{27}$ :

$$
\mathrm{V}_{\mathrm{BTPS}}=\mathrm{V}_{\mathrm{ATPS}} \times \frac{273+\mathrm{Tpt}}{273+\mathrm{TPT}} \times \frac{\mathrm{Pb}-\mathrm{PH}_{2} \mathrm{OPT}}{\mathrm{Pb}-\mathrm{PH}_{2} \mathrm{Opt}}
$$

where VATPS = volume at atmospheric temperature and pressure, $\mathrm{Tpt}=$ patient's temperature $\left(37^{\circ} \mathrm{C}\right)$, TPT $=$ temperature of the pneumotachometer, $\mathrm{Pb}=$ barometric pressure, $\mathrm{PH}_{2} \mathrm{OPT}=$ partial pressure of water vapour at head temperature of pneumotachograph, and $\mathrm{PH}_{2} \mathrm{Opt}=$ partial pressure of water vapour at temperature of patient. $\mathrm{PH}_{2} \mathrm{O}(\mathrm{T})$ was given by:

$$
\mathrm{PH}_{2} \mathrm{O}(\mathrm{T})=13.2-0.605 \times \mathrm{T}+0.0411 \times \mathrm{T}^{2}
$$

1 Murray AB, Hardwick DF, Pirie GE, Fraser BM. Assessing severity of asthma with Wright peak flow meter. Lancet 1977;i:708.

2 Taplin PS, Creer TL. A procedure for using peak expiratory flow rate data to increase the predictability of asthma episodes. F Asthma Res 1978;16:15-9.

3 Hetzel MR, Williams IP, Shakespeare RM. Can patients keep their own peak flow records reliably? Lancet 1979; $597-9$.

4 American Thoracic Society. Standardization of spirometry. Am Rev Respir Dis 1987;136:1285-98.

5 Gardner RM, Hankinson JL, West BJ. Evaluating commercially available spirometers. Am Rev Respir Dis 1980, 121:73-82.

6 Johns DP, Abramson M, Bowes G Evaluation of a new ambulatory spirometer for measuring forced expiratory volume in one second and peak expiratory flow rate. $A m$ Rev Respir Dis 1993;147:1245-50.

7 Clausen JL, Tisi GM, Moser KM. Methods- of evaluation of accuracy of spirometers and pneumotachographs. Med of accuracy of spirometers and

8 FitzGerald MX, Smith AA, Gaensler EA. Evaluation of "electronic" spirometers. N Engl F Med 1973;289:1283-8.

9 Gunawardena KA, Houston K, Smith AP. Evaluation of the turbine pocket spirometer. Thorax 1987;42:689-93.

10 Chowienczyk PJ, Lawson CP. Pocket-sized device for measuring forced expiratory volume in one second and forced vital capacity. BMF 1982;285:15-7.

11 Hosie HE, Nimmo WS. Measurement of $\mathrm{FEV}_{1}$ and FVC: comparison of a pocket spirometer with the Vitalograph. Anaesthesia 1988;43:233-8.

12 Jones KP, Mulee MA. Measuring peak expiratory flow in general practice: comparison of mini Wright peak flow meter and turbine spirometer BMF 1990;300:1629-31.

13 Bland JM, Altman DG. Statistical methods for assessing agreement between two methods of clinical measurement. Lancet $1986 ; 8: 307-10$

14 Evans RIII, Mullally DI, Wilson RW, et al. National trends in the morbidity of asthma in the US. Prevalence, hospitalization and death from asthma over two decades: 1965-1984. Chest 1987;91:65s-74s.

15 Gergen PJ, Weiss KB. The increasing problem of asthma in the United State. Am Rev Respir Dis 1992;146:823-4.

16 Beasley R, Cushley M, Holgate ST. A self-managemen plan in the treatment of adult asthma. Thorax 1989;44: $200-4$.

17 Charlton 1, Charlton G, Broomfield J, Muller MA. Evaluation of peak flow and symptoms self management plans for control of asthma in general practice. BMF 1990;301: 1350-9.

18 Kuwano K, Bosken CH, Pare PD, Bai TR, Wiggs BR, Hogg JC: Small airways dimensions in asthma and in chronic obstructive pulmonary disease. Am Rev Respir Dis 1993; 148:1220-5.

19 James AL, Pare PD, Hogg JC. The mechanics of airway narrowing in asthma. Am Rev Respir Dis 1989;139:242-6.

20 Bosken CH, Wiggs BR, Pare PD, Hogg JC. Small airway dimensions in smokers with obstruction to airflow. $A m$ Rev Respir Dis 1990;142:563-70.

21 Task Force Report, US Department of Health and Human Services. Epidemiology of respiratory disease. NIH Publication, 1980:81-201.

22 Miller MR, Dickinson SA, Hitchings DJ. The accuracy of portable peak flow meters. Thorax 1992;47:904-9.

23 Miller MR, Pincock AC. Linearity and temperature control of the Fleisch pneumotachograph. f Appl Physiol 1986; 60:710-5.

24 Nelson SB, Gardner RM, Crapo RO, Jensen RL. Performance evaluation of contemporary spirometers. Chest 1990;97:288-97.

25 Pincock AC, Miller MR. The effect of temperature on recording spirograms. Am Rev Respir Dis 1983;128:894-8.

26 Miller MR, Sigsgaard T. Prevention of thermal and condensation errors in pneumotachographic recordings of the maximal forced expiratory manoeuvre. Eur Respir $\mathcal{F} 1994$ 7:198-201.

27 Turney SZ, Blumenfeld W. Heated Fleisch pneumotachometer: a calibration procedure. $\mathcal{F}$ Appl Physiol 1973; 34:117. 